\title{
Which Stock Exchange Leads the Other: Comparison Between US, Australia, Euro Zone and UK
}

\author{
Gholamreza Zandi ${ }^{1}$, Muhammad Usman Javaid ${ }^{2}$, Urooj Anwar ${ }^{3} \&$ Muhammad Umar Islam ${ }^{3}$ \\ ${ }^{1}$ Universiti Kuala Lumpur Business School, Malaysia \\ ${ }^{2}$ Lahore Centre of Excellence in Islamic Banking and Finance, University of Lahore, Lahore, Pakistan \\ ${ }^{3}$ School of Accounting and Finance, Asia Pacific University of Technology and Innovation, Kuala Lumpur, \\ Malaysia \\ Correspondence: Muhammad Umar Islam, School of Accounting and Finance, Asia Pacific University of \\ Technology and Innovation, Kuala Lumpur, Malaysia.
}

Received: April 30, 2019

doi:10.5430/ijfr.v10n5p250
Accepted: May 30, 2019

Online Published: June 11, 2019

URL: https://doi.org/10.5430/ijfr.v10n5p250

\begin{abstract}
Recently, Financial linkages among the most advanced countries are being explored. It is very crucial matter for investors, regulators and government alike. For investor so that they can effectively manage their portfolio and for regulators to implement right policies. However, there is lack of study on identifying existence of the financial linkages and measuring direction and strength of causality among the most advanced countries based on the most updated .Hence, this paper examines linkages between stock markets of four advanced stock markets (the United States, Australia , Euro zone and UK) during the period of January 2004 to December 2013. The method applied are the error correction and variance decompositions technique including recently improved "long run structural modelling (LRSM)". Our findings, based on the above mentioned rigorous techniques, tend to suggest that there is direction of causation largely from U.K, and Euro Area and lowly from Australia to the US.
\end{abstract}

Keywords: financial linkages, stock exchange, economic growth

\section{Introduction}

Financial crisis 2007 known as Global Financial Crisis is still continuing to show its effects and has drawn a lot of attention to financial linkages as the main cause of spillovers from one economy to the others, especially among the advanced market countries. The credit crunch arising from the U.S. mortgage markets led to downsize of world financial markets and the largest global recession after great depression. Since late 2009 financial crisis in the Eurozone has begun by leading to high global financial volatility again after increasing role of recent globalization of finance. Thus, whereas the recent crisis showed the global significance of stability of large-size financial markets, interconnectedness among other advanced financial markets based on the most updated data is empirically not deeply investigated. It is the fact that the global financial systems have become more and more integrated in advanced markets especially in the last decade. This could be attributed to financialization that took place after consistent deregulation of the market in the US. Cross selling of the products to different markets have distributed the risk worldwide. Now issue of how different size of shocks to an advanced equity markets affects rest of foremost developed markets have become very important question for policy makers and financial investors to take necessary cautions for regulatory purposes and evaluate investment opportunities. Although there had been many empirical researches and theoretical approaches to estimate what explains movement of prices in equity markets as consequence of systematic linkages with different equity markets, the United States, Australia, Euro Area and the United Kingdom are appeared to be leading global hubs of equity markets by explaining the price movement in stock market of their peripheries. However, explaining interrelation among these four most developed stock market has been more difficult to explain. Since today world's majority of advanced economies such as the U.S., U.K, and Eurozone countries has been undergoing global financial crisis, global financial markets in last several years have been witnessing very unique moments of having large shocks in leading stock markets. Using the data reflecting such financial environment might help to empirically identify these financial spillovers among the most advanced economies better. As conclusion, based on the most updated data which reflecting large shocks in leading stock markets, the paper aims to identify spillover in four systematic equity markets, namely the United States, the United 
Kingdom, Australia and Euro Area as subject carries global importance since financial fragility of any of those countries might affect future of financial markets large number of countries severely which we need to shed light on this paper.

\section{Literature Review}

We are concerned with the four leading equity markets that consists of the United States, Euro Area, Australia, and the United Kingdom. These four systemic markets are the most advanced and integrated financial markets representing the majority share of the world market capitalization. In terms of market capitalization, The United States has a remarkably larger equity market capitalization than the other three countries. Although the United States itself is the most dominant equity market, if the United Kingdom and Euro Area is taken into account together due to their higher interconnectedness, their total market capitalization is slightly less than the United States (Ramuhulu \& Chiranga 2018). However, when value of share turnover is the matter, the United States is notably larger than even overall turnover in Euro Area, Australia and the United Kingdom. To investigate the linkages among these four advanced financial markets, we study prices of leading equity indices. Weekly index prices of the following indices has been used: EURO First 300 excluding UK (FTEUXUK), ASX 200 (ASX200), FTSE (FTSE), and S\&P 500 (SPCOMP). The sample spans January 1st, 2004 to December 31st, 2013 which contains 470 observations in four systematic countries. These indices are chosen since they contain leading stocks with large capitalization in domestic markets and represents most of price movements in all stock market. The data contains pre-Global Financial Crisis (2003 - 2007) post-2007 U.S. Financial Crisis (2007 - 2010) and post-2009 Euro Area Crisis (2009 - 2012) and that will enable us to reach more comprehensive conclusion by identifying causality accurately because of having large shocks in advanced equity markets in our data. There are several reasons to choose weekly data for our study. It enable us to study complete time series by reducing the issue of missing data because of holidays, closed markets etc. Secondly, different opening and closing times across the day can lead to biased results.Finally, using weekly data is more appropriate for making macroeconomics analysis because it enable to investigate macroeconomic impacts in several weeks rather than days (Xuan, 2018). Table 1 provides hint about possible linkage among four leading stock market indices.It draws our attention that correlation between Euro Area (FTEUXUK) and rest three countries is always higher than 0.90.Australia seems to have lowest correlation with stock markets in other three countries. There is high integration in European Markets with high correlation with 0.92, yet European and U.S. equity market also seems to have high integration with more than 0.92 correlation.

Table 1. Correlation of weekly leading stock markets

\begin{tabular}{lllll}
\hline & \multicolumn{4}{l}{ Equity Returns } \\
\cline { 2 - 5 } & FTSE & FTEUXUK & ASX200 & SPCOMP \\
\hline FTSE & 1 & $\cdot$ & $\cdot$ & $\cdot$ \\
\hline FTEUXUK & 0.919 & 1 & $\cdot$ & $\cdot$ \\
\hline ASX200 & 0.732 & 0.911 & 1 & $\cdot$ \\
\hline SPCOMP & 0.928 & 0.924 & 0.799 & 1 \\
\hline
\end{tabular}

Several studies incorporating empirical data from different market have shown different results. Arshanapalli and Doukas (1993) found evidence of cointegration between stock prices of the USA, Germany, UK, France and Japan. Masih and Masih (1997) found cointegration between five different markets. Wu and Su (1998) also found significant relationship between US, Japan Uk and Hong kong Stock. Empirical Floros (2005) presents an empirical analysis of the short- and long-term relationships among stock prices in the US, Australia and the UK based on data from 1988 to 2003. Granger causality show unidirectional causalities between S\&P 500 and FTSE-100, and S\&P 500. Bayoumi and Bui (2012) uses a novel variant of identification through heteroscedasticity to estimate spillovers across U.S., Euro area, Japan, and UK government bond and equity markets in a vector autoregression by using data between 2000 and 2009. The findings suggest that U.S. financial shocks reverberate in advanced stock markets more strongly than shocks from other regions, including the Euro area and the United Kingdom. On the other hand,inward spillovers to the U.S. from advanced stock markets are minimal (Riaz \& Riaz 2018). Bayoumi and Bui (2012) also finds two-way spillovers between the UK and Euro area financial markets(Razak, Sarpan \& Ramlan 2018). 
On the other hand, Islam (2013) investigated interrelationships among the four developed equity market since 2007 Global Financial Crisis by using daily and weekly data from the following indices; S\&P 500 Index for US, the FTSE Index for UK, the DAX for Germany, and Nikkei for Japan. In the paper, strong unidirectional causality has been detected from the US market to the UK market; and from the German market to the UK and to the US market by applying the Granger-causality tests(Rismayadi \& Maemunah 2018). Although there is rich literature on our reseach topic, they mostly reached different conclusions in identifying global financial linkage .Hence, there is clear unresolved discussion on identifying financial linkage amoung advanced economies. Additionally, whereas some studies did not take Euro Crisis period or U.S. Financial Crisis into account, some studies did not include the period before crisis into their analysis. Our paper attempts to investigate financial linkage among advanced stock markets for period before crisis, U.S. Financial Crisis and Euro Crisis to give most updated findings to explain global direction of spillover and shed more light on such unresolved discussion

\section{Methodology}

This research paper uses time series technique, namely, cointegration, error correction modelling and variance decomposition, for finding empirical evidence to show theoretical relationship among leading stock markets and identify direction of the spillover from one equity market to another. Firstly, mostly variables related with finance indicators including stock market indices are non-stationary which means that performing ordinary regression on the variables will lead to statistically misleading results during interpreting t-ratios and F statistics(Yaraghi \& Shafiee 2018). Applying regressions on the differenced form of these variables will solve one problem, yet by testing only short run relation, the regression will not be testing long run theoretical relationship among variables any more.Secondly, based on Akaike Information Criterion (AIC) and Schwarz Bayesian Criterion (SBC), the optimum order of the vector autoregressive (VAR) model is determined. The order given will be used in the third step subject to certain conditions(Qoqiauri \& Qoqiauri 2017). The third step is testing cointegration. Cointegration test whether there is a long run theoretical relationship among variables or not.As fourth step, Long Run Structural Modelling (LRSM) is used to test long run coefficients of variables against the theoretically expected values whether the variables are significant or not. First four steps is applied to test theory and in order to test causality, we have additional four steps more. In order to test direction of financial spillover in equity markets, Vector Error Correction Model (VECM) will enable us to learn whether a variable is exogenous (leader) or endogenous (follower).As sixth step, Variance Decompositions (VDCs) help us to identify relative exogeneity and endogeneity of indices. Impulse Response Function (IRF) is the next step which enables us when a variable is shocked, we can see the impact on other variable which is similar to VDC, yet the result is expressed in graphical form. Final step is Persistence profile which is a system wide shock, where the shock comes from the external source to our cointegrating vectors and we see the time horizon required for variables to get back to equilibrium.

\subsection{Testing Stationary of Variables}

We begin our empirical testing by determining the stationary of the variables used. In order to proceed with the testing of cointegration later, ideally, our variables should be $I(1)$, in that in their original level form, they are non-stationary and in their first differenced form, they are stationary.The differenced form for each variable used is created by taking the difference of their log forms (Purwanto, Chotimah \& Mustofa 2018). For example

$$
\operatorname{DFTSE}_{t}=\operatorname{LFTSE}_{t}-\operatorname{LFTSE}_{t-1} .
$$

We then conducted the Augmented Dickey-Fuller(ADF) test on each variable (in both level and differenced form).The table below summarizes the results.See Appendix $1 \mathrm{~A}$ to $1 \mathrm{H}$ for details.

Table 2. Augmented dickey fuller test

\begin{tabular}{lllll}
\hline Variable & \multicolumn{2}{c}{ Test Statistics } & $\begin{array}{l}\text { Critical } \\
\text { Value }\end{array}$ & Implication \\
\cline { 2 - 4 } & AIC & SBC & & \\
\hline \multicolumn{2}{l}{ Variables In Level Form } & & & \\
\hline LFTSE & -2.3261 & -2.3261 & -3.4214 & Variable is non-stationary \\
\hline LFTEUXUK & -1.7398 & -1.7398 & -3.4214 & Variable is non-stationary \\
\hline LASX200 & -1.8104 & -1.8104 & -3.4214 & Variable is non-stationary \\
\hline LSPCOMP & -2.2259 & -2.3529 & -3.4214 & Variable is non-stationary \\
\hline
\end{tabular}




\begin{tabular}{lllll}
\hline \multicolumn{4}{l}{ Variables In Differenced Form } & \\
\hline DFTSE & -22.2584 & -22.2584 & -2.8681 & Variable is stationary \\
\hline DFTEUXUK & -22.1746 & -22.1746 & -2.8681 & Variable is stationary \\
\hline DASX200 & -21.7767 & -21.7767 & -2.8681 & Variable is stationary \\
\hline DSPCOMP & -13.0755 & -14.4128 & -2.8681 & Variable is stationary \\
\hline
\end{tabular}

Relying mainly on the AIC and SBC criteria, the result that can be made from above results is that all variables we are using for this analysis are $\mathrm{I}(1)$, and thus we may continue with testing of cointegration. It is also worth to mention that determining significance is based on comparing AIC and SBC results to $\% 95$ critical value ADF regression order is also chosen based on the highest computed value for AIC and SBC. Even in the case that AIC and SBC corresponding t-statistic values are different, they are all satisfying I(1) conditions

Table 3. Phillips-Perron test

\begin{tabular}{lcll}
\hline Variable & Coefficient & Standard Error & T-ratio [Prob] \\
\hline Variables In Level Form & & \\
\hline LFTSE & -0.016 & 0.010 & $-1.56[0.119]$ \\
\hline LFTEUXUK & -0.009 & 0.006 & $-1.54[0.121]$ \\
\hline LASX200 & -0.008 & 0.005 & $-1.45[0.146]$ \\
\hline LSPCOMP & -0.016 & 0.009 & $-1.82[0.069]$ \\
\hline Variables In Differenced Form & & \\
\hline DFTSE & -1.028 & 0.068 & $-15.01[0.000]$ \\
\hline DFTEUXUK & -1.021 & 0.072 & $-14.05[0.000]$ \\
\hline DASX200 & -1.017 & 0.074 & $-13.68[0.000]$ \\
\hline DSPCOMP & -1.145 & 0.112 & $-10.18[0.000]$ \\
\hline
\end{tabular}

Phillips-Perron test is correcting both heteroscedasticity and autocorrelelation problems by using Newey-West adjusted variance method during testing whether a variable is stationary or not. Phillips-Perron results suggest that $\log$ forms of variables, namely LFTSE, LFTEUXUK, LASX200 and LSPCOMP variables are non-stationary while difference forms of them, DFTSE, DFTEUXUK, DASX200 and DSPCOMP are stationary. That is confirming our result in ADF test.

\subsection{Determination of Order of the Var Model}

Before proceeding with test of cointegration, we need to first determine the order of the vector auto regression(VAR), that is, the number of lags to be used. As per the table below, results show that AIC recommends order of 3 whereas SBCfavors 1 lag (see Appendix 2A for details).

Table 4. Selection of order of VAR

\begin{tabular}{lll}
\hline & \multicolumn{2}{l}{ Choice Criteria } \\
\cline { 2 - 3 } & AIC & SBC \\
\hline Optimal Order & 3 & 1 \\
\hline
\end{tabular}

Given this apparent conflict between recommendation of AIC and SBC, we address this in the following manner. First, we checked for serial correlation for each variable and obtained the following results.See Appendix $2 \mathrm{~B}-2 \mathrm{E}$ for details. 
Table 5. Autocorrelation diagnostic test

\begin{tabular}{lll}
\hline Variable & Chi-Sq p-value & Implication (at 10\%) \\
\hline DFTSE & 0.685 & There is no serial correlation \\
\hline DFTEUXUK & 0.234 & There is no serial correlation \\
\hline DASX200 & 0.523 & There is no serial correlation \\
\hline DSPCOMP & 0.328 & There is no serial correlation \\
\hline
\end{tabular}

As evident from Table 5, there is no auto-correlation in any variable. Normally, choosing lower order might lead to auto-correlation, yet our serial correlation test suggested that there is no autocorrelation in any variable(Riyanti, 2018). The disadvantage of taking higher order is that we risk over-parameterization. Considering the trade off of lower and higher orders, we decided to choose the mid of suggested AIC and SBC VAR order, VAR order of 2.

\subsection{Testing Cointegration}

Once we have established that the variables are I(1) and determined the optimal VAR order as 2 , we are ready to test for cointegration. As depicted in the table below, Johansen's log likelihood maximal eigenvalue and trace test statistics based on cointegration with unrestricted intercepts and restricted trends in the VAR.

Table 6. Johansen ML results for multiple cointegrating vectors

\begin{tabular}{|c|c|c|c|c|}
\hline H0 & H1 & Statistics & $95 \%$ Crit. & 90\% Crit. \\
\hline \multicolumn{5}{|c|}{ Maximal Eigenvalue Statistics } \\
\hline$r=0$ & $\mathrm{r}=1$ & 31.700 & 31.790 & 29.130 \\
\hline $\mathrm{r}<=1$ & $r=2$ & 21.544 & 25.420 & 23.100 \\
\hline \multicolumn{5}{|c|}{ Trace Statistics } \\
\hline$r=0$ & $\mathrm{r}>=1$ & 63.957 & 63.000 & 59.160 \\
\hline $\mathrm{r}<=1$ & $r>=2$ & 32.256 & 42.340 & 39.340 \\
\hline Rank & Maximized LL & AIC & SBC & HQC \\
\hline $\mathrm{r}=0$ & 4964.5 & 4944.5 & 4903.0 & 4928.2 \\
\hline$r=1$ & 4980.4 & 4952.4 & 4894.3 & 4929.5 \\
\hline $\mathrm{r}=2$ & 4991.1 & 4957.1 & 4886.6 & 4929.4 \\
\hline$r=3$ & 4994.1 & 4956.1 & 4877.3 & 4925.1 \\
\hline$r=4$ & 4996.5 & 4956.5 & 4873.5 & 4923.9 \\
\hline
\end{tabular}

From the result we could based on eigenvalue value statistic at one cointegration in $90 \%$ critical value and trace statistics implies there is one cointegration in $95 \%$ and $90 \%$ critical value. Whereas Schwarz Bayesian Criterion (SBC) and Hannan and Quinn Criterion (HQC) indicates that there is one cointegration, Akaike Information Criterion (AIC) and Maximum LL suggests that number of cointegration is two. Based on established economic theory, we are inclined to believe that there is one cointegrating vector as intuition as well as our knowledge on contemporary equity markets that if an equity market is developed and efficient, it is more integrated to global equity markets.Based on the above statistical result as well as our insight, for the purpose of this study, we shall assume that there is one cointegrating vector, or relationship.

Table 7. Engle-Granger cointegration test

\begin{tabular}{llllll}
\hline & Test Statistic & LL & AIC & SBC & HQC \\
\hline DF & -3.282 & 1238.3 & 1237.3 & 1235.2 & 1236.5 \\
\hline
\end{tabular}




\begin{tabular}{llllll}
\hline ADF(1) & -1.958 & 1278.4 & 1276.4 & 1272.3 & 1274.8 \\
\hline ADF(2) & -1.916 & 1278.4 & 1275.4 & 1269.2 & 1273.0 \\
\hline ADF(3) & -1.625 & 1282.0 & 1278.0 & 1269.7 & 1274.7 \\
\hline ADF(4) & -1.698 & 1282.3 & 1277.3 & 1266.9 & 1273.2 \\
\hline
\end{tabular}

$* 95 \%$ critical value for the Dickey-Fuller statistic $=-4.1232$

By analyzing Engle-Grenger cointegration test and based on highest AIC and SBC values, unlike Johansen cointegration test, it is concluded that there is no cointegration among variables (Ping, 2017; Yildirim, Elban \& Yildirim 2018). However, Johansen test applies maximum likelihood and can test more than one cointegration.That is why, we will continue our tests based on Johansen cointegration method. Statistically, Johansen cointegration test result indicates that the variables we have chosen, in some combination, result in a stationary error term. The economic interpretation in our view, is that the 4 indices are theoretically related, in that they move together, in the long term. In other words, the 4 indices are cointegrated, that is, their relations to one another is not merely spurious or by chance. This conclusion has important implication for investors. Given that these stock markets are cointegrated, the opportunity to gain abnormal profits via portfolio diversification is limited. This is to say, while investing in short term, an investor can improve returns relative to risk by geographically diversifying his equity investment, this strategy would not yield that investor consistently abnormally returns over long run. This is because cointegrated markets would eventually realign themselves into a long term (theoretical) relationship with one another.

\subsection{Long Run Structural Modelling (LRSM)}

Next, we attempt to quantify this apparent theoretical relationship among the indices. We do this in order to compare our statistical findings with theoretical expectations. Relying on the Long Run Structural Modelling (LRSM) component of MicroFit, and normalizing our variable (index) of interest, the FTSE Index, we initially obtained the results in the following table (see Appendix 4A). Calculating, the t-ratios manually, we found two variables (indices) to be significant - LFTEUXUK and SPCOMP

Table 8. Exact and over identifying restriction on the cointegrating vector

\begin{tabular}{lllll}
\hline & Panel A & \multicolumn{3}{l}{ Panel B } \\
\hline LFTSE & $-2.60^{* * *}$ & $(0.60)$ & $-2.47^{* * *}$ & $(0.45)$ \\
\hline LFTEUXUK & $1.14^{*}$ & $(0,69)$ & $0.92^{* * *}$ & $(0.29)$ \\
\hline LASX200 & -0.12 & $(0,35)$ & 0.00 & $(*$ None* $)$ \\
\hline LSPCOMP & 1.00 & $(*$ None*) & 1.00 & $(*$ None*) \\
\hline Trend & $0.89 * * *$ & $(0.22)$ & $0.92^{* * *}$ & $(0.19)$ \\
\hline Log-Likelihood & 4980.4 & & 4980.4 & \\
\hline Chi-Square (p-value) & None & & $0.140 .70)$
\end{tabular}

*Indicates significance at $10 \%$ level. ***Indicates significance at $1 \%$ level.

- Values in brackets are standard error

The output in Table 8 shows the maximum likelihood estimates subject to exactly identifying (Panel A) and overidentifying (Panel B) restrictions.The Panel A estimates show that all variable except LASX200 is significant which can be considered as plausible due to geographical difference and different financial dynamics in Australia after 1990s.Again due to impact of US financial crisis on Euro Area,it was plausible to expect a positive relation between EURO First 300 (excluding UK) and S\&P 500,yet it is interesting that our result shows that there is negative relation between FTSE 100 and S\&P 500 indices. Theoretically, it is very difficult to explain such result.There might be statistical factors leading such misleading result since at beginning we found very high positive correlation between two variables which made us not to expect a negative relation between two variables. In over identifying restriction on coefficient of LASX200 $=0$ is not rejected in $10 \%$ significance level since p-value is more 
than 0.10. As a result, we proceed with Panel B and from the above analysis, we arrive at the following cointegrating equation (numbers in paranthesis are standard deviation):

$$
\mathrm{SPCOMP}+2.47 \mathrm{FTSE}-0.92 \mathrm{FTEUXUK} \longrightarrow \mathrm{I}(0)
$$

\subsection{Vector Error Correction Model (VECM)}

From our analysis thus far, we have established that at least three indices are cointegrated to a significant degree FTSE 100, S\&P 500, and EURO First 300 (Excluding UK).However, the cointegrating equation reveals nothing about causality, that is, which index is the leading variable and which is laggard variable. Information on direction of Granger-causality can be particularly useful for investors. By knowing which variable is exogenous and endogenous, investors can better forecast or predict expected results of their investment. Typically, an investor would be interested to know which index is the exogenous variable because then the investor would closely monitor the performance of that index as it would have significant bearing on the expected movement of other indices in which the investor has invested. This exogenous index would be the index of interest to the investor. The next part of our analysis involves the Vector Error Correction Model (VECM). Here, in addition to decomposing the change in each variable short-term and long-term components, we are able to ascertain which variables are in fact exogenous and which are endogenous. The principle in action here is that of Granger-causality, a form of temporal causality where we determine the extent to which the change in one variable is caused by another variable in a previous period. By examining the error correction term, $e_{t-1}$, for each variable, and checking whether it is significant, we found that there is only one endogenous variable, $\mathrm{S} \& \mathrm{P} 500$, as depicted in the table below. The other variables were found to be exogenous.

Table 9. Vector error correction models

\begin{tabular}{lllllllll}
\hline Dependent Variable & DFTSE & \multicolumn{4}{c}{ DFTEUXUK } & \multicolumn{2}{c}{ DASX200 } & \multicolumn{2}{c}{ DSPCOMP } \\
\hline DFTSE(-1) & -0.071 & $(0.114)$ & -0.020 & $(0.121)$ & 0.321 & $(0.142)$ & 0.144 & $(0.122)$ \\
\hline DFTEUXUK(-1) & -0.093 & $(0.121)$ & -0.146 & $(0.128)$ & -0.218 & $(0.149)$ & 0.024 & $(0.129)$ \\
\hline DASX200(-1) & 0.001 & $(0.048)$ & 0.004 & $(0.051)$ & -0.165 & $(0.060)$ & -0.018 & $(0.051)$ \\
\hline DSPCOMP(-1) & 0.174 & $(0.072)$ & 0.158 & $(0.076)$ & 0.204 & $(0.089)$ & -0.263 & $(0.077)$ \\
\hline ECM(-1) & -0.042 & $(0.046)$ & 0.045 & $(0.049)$ & 0.083 & $(0.057)$ & $0.104^{*}$ & $(0.049)$ \\
\hline Chi-square SC(1) & 18.514 & {$[0.000]$} & 10.470 & {$[0.001]$} & 1.596 & {$[0.206]$} & 11.142 & {$[0.001]$} \\
\hline Chi-square FF(1) & 3.729 & {$[0.053]$} & 0.220 & {$[0.639]$} & 0.581 & {$[0.446]$} & 7.7671 & {$[0.005]$} \\
\hline Chi-square N(2) & 363.831 & {$[0.000]$} & 243.000 & {$[0.000]$} & 328.1 & {$[0.000]$} & 4528.2 & {$[0.000]$} \\
\hline Chi-square Het(1) & 22.787 & {$[0.000]$} & 34.892 & {$[0.000]$} & 34.373 & {$[0.000]$} & 11.403 & {$[0.001]$} \\
\hline
\end{tabular}

*indicates $5 \%$ significance level

The implication of this result is that as far as the analyzed markets are concerned, U.S. equity market investors would closely monitor movements in FTSE 100, ASX200 and EURO First 300 Excluding UK because these mentioned three indices, being exogenous variables, will significantly affect movements in S\&P 500 indice. Likewise, news, events and developments that are likely to affect the FTSE 100, ASX200 and EURO First 300 (Excluding UK) 
would be of interest to that investor. In addition, the VECM produces a statistic that may be of interest to investors.

The coefficient of $e_{t-1}$ tell us how long it will take to get back to long term equilibrium if that variable is shocked.

The coefficient represents proportion of imbalance corrected in each period. For instance, in the case the S\&P 500 index, the coefficient is 0.104 . This implies that when there is a shock applied to this index, it would take average 10 weeks for the index to get back into equilibrium with the other indices.

\subsection{Variance Decomposition (VDC)}

While we have established that S\&P 500 is the endogenous index, we have not been able to say anything about the relative exogeneity of the remaining indices. As VECM is not able to assist us in this regard, we turn our attention to variance decomposition (VDC).Relative endogeneity can be measured in the following way.VDC decomposes the variance of forecast error of each variable into proportions attributable to shocks from each variable in the system, including its own. The least endogenous variable is thus the variable whose variation is explained mostly by its own past.We started out applying, orthogonalized VDCs and obtained the following results (see Appendix 6A to 6D).

Table 10. Orthogonalized variance decompositions

\begin{tabular}{|c|c|c|c|c|}
\hline Weeks Forecast at Horizon & $\triangle F T S E$ & $\triangle F T E U X U K$ & $\triangle A S X 2000$ & $\triangle S P C O M P$ \\
\hline \multicolumn{5}{|c|}{ Relative Variance in $\triangle F T S E$} \\
\hline 12 & 98.94 & 0.16 & 0.01 & 0.89 \\
\hline 25 & 98.49 & 0.36 & 0.01 & 1.10 \\
\hline 50 & 98.00 & 0.60 & 0.01 & 1.39 \\
\hline \multicolumn{5}{|c|}{ Relative Variance in $\triangle F T E U X U K$} \\
\hline 12 & 90.00 & 9.89 & 1.88 & 8.61 \\
\hline 25 & 92.46 & 7.45 & 3.04 & 4.64 \\
\hline 50 & 94.23 & 5.67 & 4.11 & 4.60 \\
\hline \multicolumn{5}{|c|}{ Relative Variance in $\triangle A S X 200$} \\
\hline 12 & 57.46 & 1.32 & 41.02 & 0.17 \\
\hline 25 & 60.03 & 0.77 & 39.09 & 0.10 \\
\hline 50 & 61.89 & 0.43 & 37.62 & 0.05 \\
\hline \multicolumn{5}{|c|}{ Relative Variance in $\triangle S P C O M P$} \\
\hline 12 & 80.74 & 1.74 & 0.23 & 17.28 \\
\hline 25 & 84.98 & 0.84 & 0.26 & 13.92 \\
\hline 50 & 87.85 & 0.41 & 0.29 & 11.45 \\
\hline
\end{tabular}

For the above tables, row read as the percentage of the variance of forecast error of each variable into proportions attributable to shocks from other variables (in columns), including its own. The columns read as the percentage in which that variable contributes to other variables in explaining observed changes. The diagonal line of the matrix represents the relative exogeneity.According to these results, the ranking of indices by degree of exogeneity is as per the table below.

Table 11. Ranking of exogeneity

\begin{tabular}{ll}
\hline No & Index \\
\hline 1 & FTSE 100 \\
\hline
\end{tabular}




\begin{tabular}{ll}
\hline 2 & ASX200 \\
\hline 3 & S\&P 500 \\
\hline 4 & EURO First 300 (excluding UK) \\
\hline
\end{tabular}

Initially, we found this result somewhat puzzling. This is because, from the previous VECM analysis, we determined that S\&P500 was the only endogenous variable, and yet, in the VDC, it is only third in rank in terms of relative endogeneity. In order to make sense of this result, we need to recognize two important limitations of orthogonalized VDCs. Firstly it assumes that when a particular variable is shocked all other variables are switched off. Secondly, and more importantly, orthogonalized VDCs do not produce a unique solution. The generated numbers are dependent upon the ordering of variables in the VAR. Typically, the first variable would report the highest percentage and thus would likely to be specified as the most exogenous variable. This is the case in our data, where FTSE 100, which appears first in the VAR order, is reported to be the most exogenous. To experiment with the extent to which this is true (that orthogonalized VDCs are "biased" by the ordering of variables), we switched S\&P 500, which appears third and re reran the orthogonalized VDC. The result confirmed our suspicion (see Appendix 6I).For forecast horizon of 25 weeks, for S\&P 500, the percentage of variation explained by its own jumped from $13.92 \%$ to $92.02 \%$ Following this discovery, we decided to rely instead on Generalized VDCs, are invariant to the ordering of variables. We obtained results as per Appendix 6F to 6I.In interpreting the numbers generated by the Generalized VDCs, we need to perform additional computations. This is because the numbers do not add up to 1.0 as in the case of orthogonalized VDCs. For a given variable, at a specified horizon, we total up the numbers of the given row and we then divide the numbers for that variable by the computed total. In this way, the numbers in a row will now add up to 1.00 or $100 \%$. The tables below show the result.

Table 12. Generalized variance decompositions

\begin{tabular}{lllll}
\hline Weeks Forecast at Horizon & $\Delta F T S E$ & $\Delta F T E U X U K$ & $\Delta A S X 200$ & $\Delta S P C O M P$ \\
\hline $\begin{array}{l}\text { Relative Variance in } \Delta F T S E \\
\mathbf{1 2}\end{array}$ & 33.22 & 28.79 & 13.34 & 24.66 \\
\hline $\mathbf{2 5}$ & 32.81 & 28.89 & 13.28 & 25.02 \\
\hline $\mathbf{5 0}$ & 32.39 & 29.01 & 13.23 & 25.37 \\
\hline Relative Variance in $\Delta$ FTEUXUK & & & \\
\hline $\mathbf{1 2}$ & 29.39 & 32.28 & 14.67 & 23.65 \\
\hline $\mathbf{2 5}$ & 30.19 & 31.92 & 14.73 & 23.16 \\
\hline $\mathbf{5 0}$ & 30.84 & 31.63 & 14.77 & 22.75 \\
\hline Relative Variance in $\mathbf{\Delta A S X 2 0 0}$ & & & \\
\hline $\mathbf{1 2}$ & 22.52 & 21.34 & 37.32 & 18.83 \\
\hline $\mathbf{2 5}$ & 23.38 & 21.42 & 36.55 & 18.65 \\
\hline $\mathbf{5 0}$ & 24.06 & 21.46 & 36.00 & 18.48 \\
\hline Relative Variance in $\Delta S P C O M P$ & & & \\
\hline $\mathbf{1 2}$ & 27.76 & 26.10 & 13.33 & 32.80 \\
\hline $\mathbf{2 5}$ & 29.07 & 25.97 & 13.48 & 31.48 \\
\hline $\mathbf{5 0}$ & 30.08 & 25.85 & 13.60 & 30.46
\end{tabular}

We can now more reliably rank the indices by relative exogeneity, as depicted in the table below. From the above results, we can make the following key observation: 
- The Generalized VDCs confirm the result of the VECM in that S\&P 500 is most endogenous variable in 25 and 50 weeks horizon.Additionaly, unlike orthogonalized VDC suggest, the most exogenous variable ASX200 indice according to generalized VDC.

- Relative rank in exogeneity is somewhat stable as time passes except the exogeneity ranking between S\&P 500 and EURO First 300 (excluding UK).However, as VECM suggests in long term relation, S\&P 500 is most endogenous.UK and Euro Area's impact might be becoming more exogenous due to ongoing financial crisis in Euro Zone

- The difference in exogeneity between indices is not susbtantial.For example, in horizon of 50 weeks, only $5.44 \%$ seperate the most exogenous variable and the least exogenous variable despite only explaining causality among four indices

- Despite ASX200 index is the most exogenous variable, more of variation in S\&P 500

- Indices are explained by EURO First 300 (excluding UK) and FTSE 100 indices.

Table 13. Ranking of exogeneity

\begin{tabular}{|c|c|c|c|}
\hline \multirow[t]{2}{*}{ No } & \multicolumn{3}{|l|}{ Variable Relative Exogeneity } \\
\hline & At Horizon =12 & At Horizon $=25$ & At Horizon =50 \\
\hline 1 & ASX200 & ASX200 & ASX200 \\
\hline 2 & FTSE 100 & FTSE 100 & FTSE 100 \\
\hline 3 & S\&P 500 & $\begin{array}{llll}\text { EURO First } 300 \text { (excluding } \\
\text { UK) }\end{array}$ & $\begin{array}{l}\text { EURO First } 300 \text { (excluding } \\
\text { UK) }\end{array}$ \\
\hline 4 & $\begin{array}{l}\text { EURO First } 300 \text { (excluding } \\
\text { UK) }\end{array}$ & S\&P 500 & S\&P 500 \\
\hline
\end{tabular}

The above result would have the following plausible implications for investors.Among the markets considered, it appears that the ASX200 is the most exogenous variable.This is followed by FTSE 100 and EURO First 300 (excluding UK) for 25 weeks and 50 weeks horizon.Although S\&P 500 indice is most endogenous variable, exogeneity of FTSE 100 and EURO First 300 (excluding UK) are very near to S\&P 500.It can be due to ongoing financial crisis in Euro Area that UK and Euro Area's impact might be becoming more exogenous.Although ASX200 is the most exogenous index, it explains variation in S\&P 500 relatively least.

\subsection{Persistence Profile}

The persistence profile illustrates the situation when the entire cointegrating equation is shocked, and indicates the time it would take for the relationship to get back to equilibritum.Here the effect of a system-wide shock on the long-relations is the focus (instead of variable-specific shock on the long-run relations is the focus instead of variable specific shocks as in the case of IRFs. The chart below shows the persistence profile for cointegrating equation of this study. The chart indicates that it would take approximately 26 weeks for the cointegrating relationship to return to equilibrium following a system-wide shock.

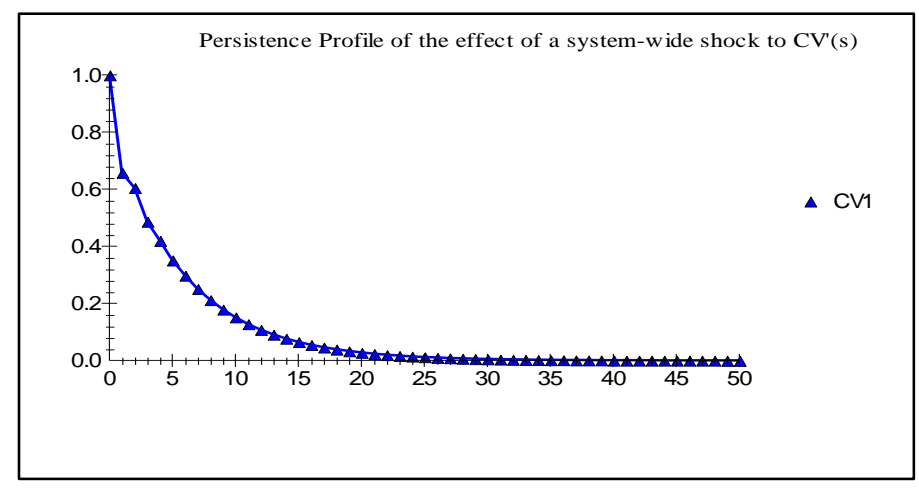

Figure 1. Persistence profile 


\section{Conclusion}

This paper has examined spillovers across equity markets in the world's most advanced markets, those of the United States, Euro area, Australia, and the United Kingdom. Although Generalized VDCs in 25 and 50 weeks horizon and VECM reach the result that S\&P 500 is most endogenous variable, Generalized VDC results shows that exogeneity of FTSE 100 and EURO First 300 (excluding UK) are slightly larger than S\&P 500. Although Euro Area, the U.K. or the U.S are affecting each other, one of any of them is not very highly dominating another. However,if there is a very large shock in any of those country rest of the countries severely can be affected severely. Australia's spillovers are generally the weakest across the equity market that are examined, although they may build over time. The European markets appear to have two-way spillovers on each other and there is evidence that Euro Area and the United Kingdom shocks have impact on the United States. If the question "In particular, does a similar size of shock to the Euro Area financial markets hit the U.S. and rest of the countries with the same impact as the Lehman one did?' is asked, our answer is yes, but they are likely to be of the slightly larger size of those seen after the collapse of Lehman Brothers.

\section{Limitation and Suggestion for Future Research}

The following are some conceivable limitations of this study and hence, presents opportunities for future research. As systematic equity markets, only the United States, the United Kingdom, Australia and Euro Area are taken into account, yet size of stocks markets in China, Hong Kong and South Korea are getting big as much as those in Eurozone countries. That is why, ignoring those large equity markets might bring limitation to explain interconnectedness of global financial system also. Finally, one limitation might be statistical limitation of applied time series techniques.In the case that there are more appropriate and more advanced tests to get more unbiased result and tackle such statistical problems for our research, it would be better to use such econometric methodologies for improvement of the study.

\section{References}

Arshanapalli, B., \& Doukas, J. (1993). International Stock Market Linkages: Evidence from the Pre- and Post-October 1987 Period. Journal of Banking and Finance, 17, 193-208. https://doi.org/10.1016/0378-4266(93)90088-U

Bayoumi, T., \& Bui, T. (2012). Do U.S. Bond And Equity Spillovers Dominate Global Financial Markets?. IMF Working Paper. https://doi.org/10.5089/9781475586633.001

Floros ,C. (2005). Price Linkages Between The U.S., Japan And U.K. Stock Markets. Swiss Society For Financial Market Research, 169-178. https://doi.org/10.1007/s11408-005-3384-2

Islam, M. (2013). Global Financial Crisis And Dynamic Linkages Between The Stock Markets of U.S., U.K., Germany And Japan: Cointegration And Causality Tests. Proceedings of 8th Annual London Business Research Conference, Imperial College, London, UK.

Masih, A. M. M., \& Masih, R. (1997). BA Comparative Analysis of the Propagation of Stock Market Fluctuations in Alternative Models of Dynamic Causal Linkages. Applied Financial Economics, 7, 59-74. https://doi.org/10.1080/096031097333853

Ping, G. (2017). Revisiting the Causal Nexus between Defense Expenditure and Economic Growth: Time Series Analysis for Saudi Arabia. Asian Journal of Economic Modelling, 5(1), 35-43. https://doi.org/10.18488/journal.8/2017.5.1/8.1.35.43

Purwanto, M. R., Chotimah, C., \& Mustofa, I. (2018). Sultan Agung's Thought of Javanis Islamic Calender and its Implementation for Javanis Moslem. International Journal of Emerging Trends in Social Sciences, 4(1), 9-14. https://doi.org/10.20448/2001.41.9.14

Qoqiauri, L., \& Qoqiauri, N. (2017). Determining issues of the economic essence and methodology of foresight. Quality Management: Search and Solutions, 42-56.

Ramuhulu, M., \& Chiranga, N. (2018). An Investigation into the Causes of Failures in Railway Infrastructure at Transnet Freight Rail-A Case of the Steel and Cement Business Unit. International Journal of Sustainable Development \& World Policy, 7(1), 8-26. https://doi.org/10.18488/journal.26.2018.71.8.26

Razak, A., Sarpan, S., \& Ramlan, R. (2018). Influence of Promotion and Job Satisfaction on Employee Performance. Journal of Accounting, Business and Finance Research, 3(1), 18-27. https://doi.org/10.20448/2002.31.18.27 
Riaz, N., \& Riaz, S. (2018). Investment and Economic Growth: A Panel Data Analysis. Asian Development Policy Review, 6(1), 20-31. https://doi.org/10.18488/journal.107.2018.61.20.31

Rismayadi, B., \& Maemunah, M. (2018). Creative Economy to Increase Community Revenue Based on Tourism Object, Medalsari Village, Pangkalan District Karawang Regency. Journal of Accounting, Business and Finance Research, 3(1), 28-35. https://doi.org/10.20448/2002.31.28.35

Riyanti, M. T. (2018). Development of Learning Devices Commercial Graphic Based Planning Project. International Journal of Education, Training and Learning, 2(1), 1-6. https://doi.org/10.33094/6.2017.2018.21.1.6

Wu, C., \& Su, Y. (1998). Dynamic Relations Among International Stock Markets. International Review of Economics and Finance, 7, 63-84. https://doi.org/10.1016/S1059-0560(99)80017-3

Xuan, D. T. (2018). Exchange Rate and Trade Balance in Vietnam: A Time Series Analysis. Asian Economic and Financial Review, 8(9), 1158-1174. https://doi.org/10.18488/journal.aefr.2018.89.1158.1174

Yaraghi, E., \& Shafiee, S. (2018). Roles of Learner Autonomy and Willingness to Communicate in Communication Strategy Use of EFL Learners. International Journal of English Language and Literature Studies, 7(3), 55-74. https://doi.org/10.18488/journal.23.2018.73.55.74

Yildirim, G., Elban, M., \& Yildirim, S. (2018). Analysis of Use of Virtual Reality Technologies in History Education: A Case Study. Asian Journal of Education and Training, 4(2), 62-69. https://doi.org/10.20448/journal.522.2018.42.62.69 